\title{
Interaction of the educational institution with the automobile labor market
}

\author{
M. Pukalo \\ Lviv Polytechnic National University \\ Corresponding author. E-mail: mari4kapukalo@gmail.com
}

Paper received 26.04.19; Accepted for publication 05.05.19.

\section{https://doi.org/10.31174/SEND-PP2019-198VII80-07}

\begin{abstract}
Enterprises can be competitive when they maintain and improve their position on the market. And also constantly support and improve the quality of products and services in the indicators important for consumers. The problems of motor transport, first of all, are the ability to provide quality transport services at a minimal cost, related to the operation of the transport process and the observance of traffic safety. On average, Ukraine has 187 cars per 1000 inhabitants. The leader is the city of Kyiv, where there are 343 vehicles per 1000 inhabitants. In the city of Lviv, this figure is 103 cars per 1,000 inhabitants [1]. Thus, the demand for workers is increasing. The lack of highly qualified specialists in the field of transport, which meet the modern and promising requirements of the labor market, is in practice encountered.Therefore, the training of such specialists is a priority area of vocational education and training institutions.
\end{abstract}

Keywords: competence, labor market, specialists in automotive engineering, quality of educational process.

Analysis of recent research and publications. Much attention has always been paid to the issues of the motor transport market, in particular, both foreign and domestic scientists. The status and possibilities of the development of the Ukrainian labor market were studied by such scientists as Kachan Ye.P., Bogdina D.P., Goril A.G., Vorotina L. I. and others. The works of such scientists are also devoted to the study of the automotive market: Danylyshyn B.M. [2], Perozi P.V. [3], Ignatyuk A.I. [4], Kashepov A.V. [5] and others. However, attention is focused on the trends of the automotive market, but its features and development prospects are not considered in modern terms.

Purpose - determining the need for interaction between educational institutions and the automotive labor market.

Materials and methods. Theoretical analysis of scientific sources and generalization of scientific literature on the research problem; the method of comparative analysis and synthesis of data synthesis, system, structural and functional methods

Results and discussion. In recent years, the imperfection of the arrangements of interaction between education and the labor market has become acutely problem in the world. Modern enterprises require that the knowledge, skills and professional competencies of staff trained by universities correspond to the requirements of a modern, innovative economy. In European countries, activity is underway to bring the system of higher education in accordance with the needs of regional labor markets.

As known, labor market - a set of economic relations between the supply and demand for labor.

Between universities and enterprises in Europe there is a complex of effective cooperation practices in the following areas:

- in the educational sphere;

- in the scientific sphere;

- in the material and technical sphere;

- in the cultural sphere.

The effectiveness of the interaction between universities and enterprises is growing significantly when enterprises move from the standpoint of third-party observers and consumers of educational services to the position of interested participants in educational and innovation processes. In this case, they promote the acquisition by stu- dents a number of professional competencies that correspond to the requirements of the modern labor market. Maximum harmonization of mutual interests of universities and enterprises promotes universities in the training of specialists and enterprises in the provision of their personnel needs.

Therefore, the introduction of these practices in the European Union allowed European universities to improve the quality of higher education in accordance with the requirements of the modern innovative economy.

The quality of education is a complex of characteristics of the educational process, which determine the consistent and practically effective formation of competence and professional consciousness. It is a certain level of knowledge and skills, mental, physical and moral development, which was achieved by graduates of the educational institution in accordance with the planned goals of education and upbringing.

Nowadays in Ukraine, the partnership between higher education institutions and business representatives is at a rather low level. The process of cooperation with enterprises is ineffective due to such factors:

- lack of understanding by universities and enterprises of the aspects of establishing effective types of cooperation;

- lack of awareness among most employers of the necessity and economic effectiveness of investment in human resources development;

- the need to introduce new forms of cooperation between universities and enterprises that meet the new economic conditions and the innovative nature of the modern economy.

But the economic situation in Ukraine has a need to bring the educational process at universities in accordance with the needs of regional labor markets. Therefore, it is important to introduce the European experience of cooperation of universities and enterprises in Ukraine, which will enable to direct professional development of the future employee in the necessary direction and with a more efficient allocation of resources.

At the same time, for different universities and different specialties, it is expedient to introduce different types of cooperation with different features depending on the region and economic factors. 
As the development of the university takes place within the framework of national policy, it determines the specifics of the development of the national educational system, rules and procedures adapted to satisfy the needs of the national economy and culture. Thus, certain problems occur associated with the loss of higher education value in the light of rapid economic development, which takes place faster than the development of competences in higher education. All this causes the urgent need of universities to develop new forms of organization of a policy of cooperation with enterprises at the international and national levels, which will help students to receive highquality, contemporary and up-to-date higher education. All this incites universities to develop new forms of organization of the policy of cooperation with enterprises at the international and national levels.

Competence is the ability of an employee to carry out certain types of work in a particular profession in a qualified manner, achieving high quantitative and qualitative results of work on the basis of his available professional knowledge, skills and abilities [6].

For an example, analyze the automotive labor market. Because this is one of the most important sectors of the economy.

Mostly, vehicle owners choose service stations (Automobile repair shop) for regular maintenance and specific repair work. Therefore, analyzing the correspondence of demand with the proposal of specialists of the motor transport profile in the labor market, research was conducted in the group of enterprises most well-known and, at present, successful ones: TZOV "Niko-zahid", "Audi Centre", TZOV "Ukrainian fuel group", company "Toyota Centre Lviv "Diamond" and garage "LYUBE".

In the process of study the enterprises, the statistics of orders were received in months for the period from 1.11 . 2016 to 01.11 .2017 . In order to prevent claims from these companies, regarding commercial data, specific names are not given. The chart of the number of services by months is given in Fig. 1.

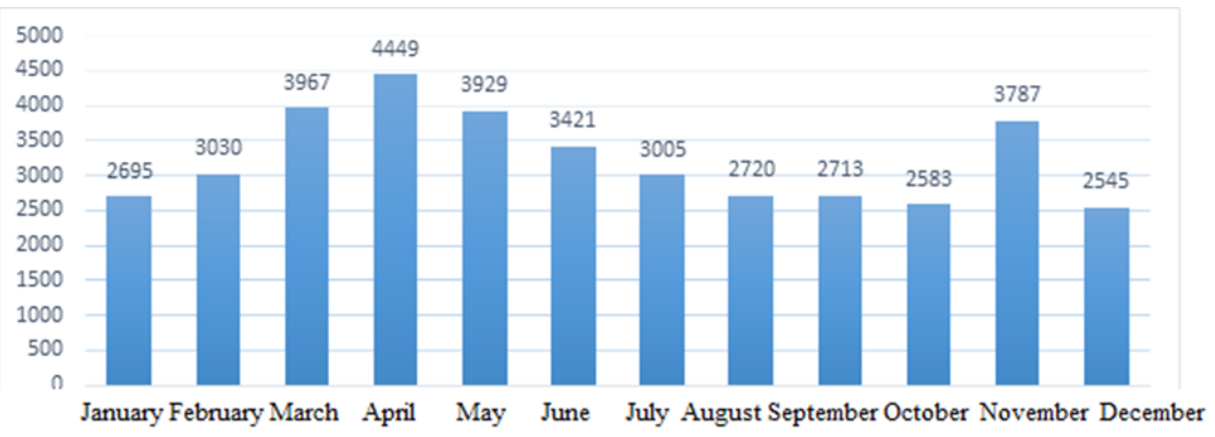

Figure 1. Number of serviced cars by months

The following data is needed to determine the level of security provided by the workers of each of the studied enterprises: load of the enterprise (orders for the year from 1.11.2016 to 1.11.2017), the number of workers (optional), the average service time for one vehicle (in accordance with the types of enterprise services). According to the received data, we determine the number of services per employee per day and time of execution of these works, taking into account the number of working days for the studied period, which is 250 days. Having Processed the data, we will graphically demonstrate the working time deviation from the normal duration (Fig. 2), which cannot exceed 8 hours per day.

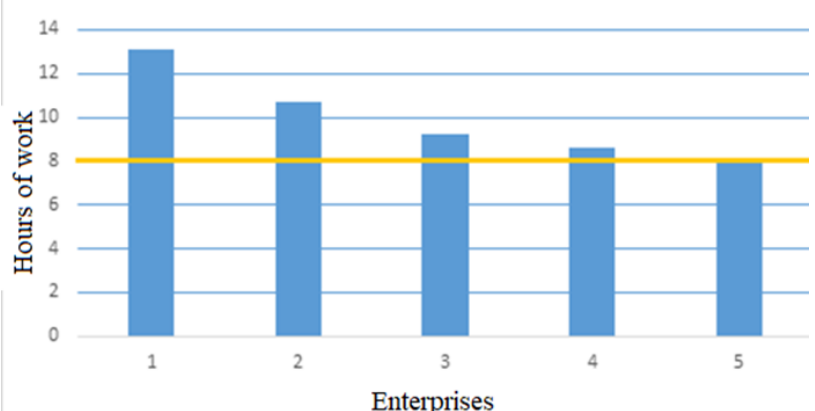

Figure 2. Work hours of one worker at Automobile repair shop in one day

It is obvious that almost all studied enterprises operate above the standard of working time. It should be argued that the demand for specialists in the motor transport profile in terms of service is relevant.

Therefore, a specialist in road transport is a popular profession in the labor market, since the high level of competition in the market of transport services leads to the need to find a rational way of transport services, substantiation of efficient transport-technological schemes of cargo delivery, the introduction of progressive forms and methods for organizing the transportation process, improvement of existing and development of advanced transport technologies.

Therefore, the interaction between the educational institution and the enterprise is very important. As the new requirements of the digital society produce new competencies.

We offer a complex of effective cooperation practices, in particular:

- participation in the formation of educational programs;

- organization of training practices and internships at enterprises;

- advanced training of university academic staff at enterprises;

- participation of specialists in productions in the process of teaching (lectures, practical classes, etc.)

- joint educational-production and research units at enterprises;

- training units in the universities for the improvement of the skills of the employees of enterprises; 
- modernization of production and training equipment for advanced technologies;

- joint research on the branch of the production activity

of enterprises;

- joint research companies;

- financial participation of enterprises in the training of specialists for their needs;

- a conclusion of tripartite agreements (studentuniversity-enterprise) for preparation of specialists with the subsequent employment of graduates

- the dual form of education;

- life-long education;

- etc.

As a result the interaction of universities and enterprises will stimulate high-level scientific and practical re- search, attracting talented and gifted individuals, and creation of a practical platform for Ukrainian universities to support the adaptation of the Ukrainian policy of cooperation between universities and enterprises to the standards adopted by the EU, as well as a favorable environment for strengthening cooperation and the exchange of ideas for such cooperation.

Conclusions. Problems of training highly skilled specialists are also relevant today, as modern infrastructure technologies set new requirements for the preparation of certain maintenance and repair services for automobiles. Therefore, the interaction of the labor market and educational institutions is one aspect of improving the quality of education. In this way, the professional competence of specialists increases.

\section{REFERENCES}

1. Motor vehicle sales in Ukraine. [Electronic resource]. Access mode: http://www.autoconsulting.com.ua/

2. Danylyshyn B.M. Machine-building in Ukraine: trends, problems, perspectives: [Monograph] / Under the congregation. Ed. Corr. NAS of Ukraine B.M. Danylyshyna - Nizhyn: "View-as" Aspect-Polygraph LLC, 2007. - 308 p.

3. Sobkevich O.V. "On realizing the potential of the machinebuilding industry in the strategy of import substitution". Analytical note [Electronic resource] / O.V. Skevich, Ye.V. Belashov - Access mode: http://www.niss.gov.ua/articles/1110/

5. Ignatyuk AI Sectoral Markets: Theory, Practice, Directions of Regulation: [monograph] / AI Ignatyuk - K.: NSC IAE, 2010. - p. 95.

6. Kashepov AV etc. Labor market: problems and solutions: monograph / AV Cushions - M .: Scientific expert, 2008 $232 \mathrm{p}$.

7. Krasilnikova V.G. Professional Pedagogy [Electronic Resource]: Distance Learning. Topic 1. Professional pedagogy is a science and a subject. Access mode: http://lubbook.org/book_303_glava_3_Tema_1.

4. Pronosis P.V. World Automotive: Contemporary Trends and Development Prospects / P.V. Prorosis // Business Inform. 2015. - No. 8. - 118-125 p. 